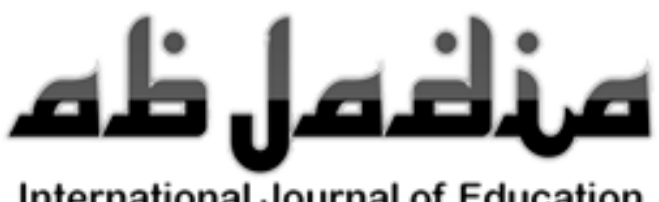

International Journal of Education

Pi) Publisher

Fakultas Ilmu Tarbiyah dan Keguruan Universitas Islam Negeri (UIN] Mualana Malik Ibrahim Malang Indonesia

2443-0587 - ISSN Online

2528-3979 - ISSN Print

(1) History Article

屯 Received : 28-07-2017

(15) Reviced : 22-08-2017

目 Accepted : 20-12-2017

\section{doi.org/ 10.18860/abj.v2i2.5361}

http://ejournal.uin-malang.ac.id/index.php/ abjadia/article/view/5361

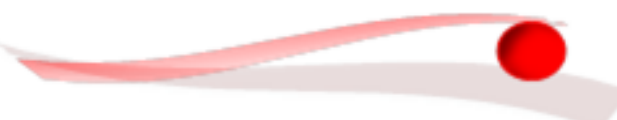

\section{Q Kholidia Yusuf}

9. Indonesia

(2) Universitas Islam Negeri Maulana Malik Ibrahim Malang Indonesia

\section{Corresponding Author}

(C) 085755389916

(1) kholidyayusuf94@gmail.com

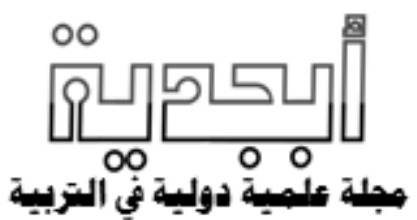

Kholidia Yusuf

Indonesia

\section{فعالية طريقة البقائين والضـالعين في ترقية مهارة

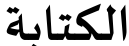

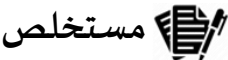 \\ في عملية تعلم اللغة العربية ، يجد الطلاب صعوبة في فهم مهارات

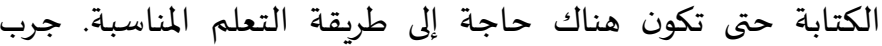

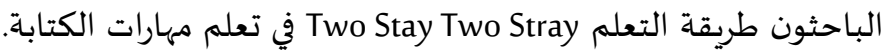

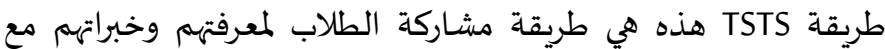

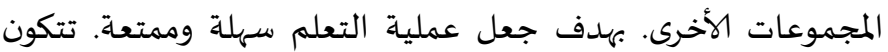

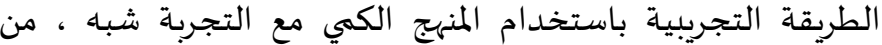

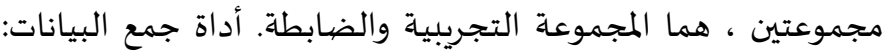 التوثيق والمراقبة والاختبار المسبق واختبار ما بعد الاختبار. كانت نتائج

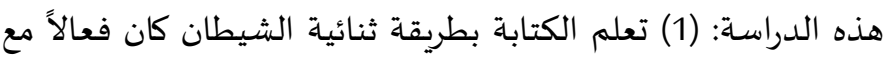

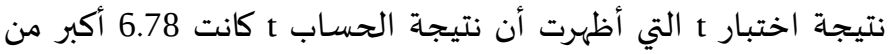

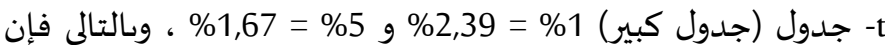 فرضية الباحث مقبولة. ج طريقة البقائين والضيالعين، مهارة الكتابة}

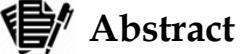

In the process of learning Arabic, students find it difficult to understand the writing skills so that appropriate learning method is needed. Researchers tried the Two Stay Two Stray learning method in learning writing skills. This TSTS method is the way students share their knowledge and experience with other groups. With the aim to make learning process easy and fun. The experimental method using quantitative approach with quasi experiment consists of 2 groups, namely experiment and control group. Instrument of data collection: documentation, observation, pre-test and post-test. The results of this study were: (1) writing learning with Two Stay Two Stray method was effective with the result of $t$-test that showed that the result of $\mathrm{t}$ arithmetic was 6.78 bigger than $\mathrm{t}$-table (significant table) $1 \%=2,39$ and $5 \%=1.67$, thus the researcher's hypothesis is acceptable.

@. Method Two Stay Two Stray, Writing Skills 


\section{صنافهل ظه \\ International Journal of Education}

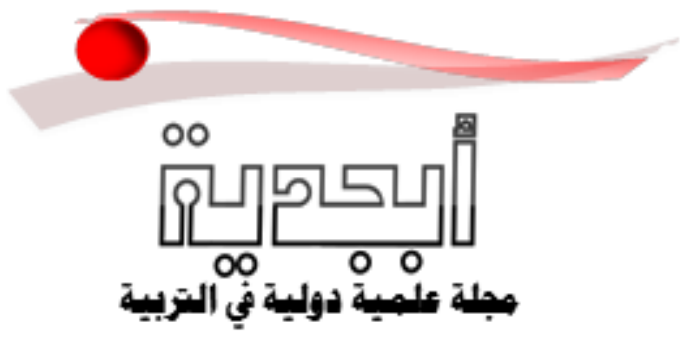

\section{Abstrak}

Dalam proses pembelajaran bahasa Arab, siswa merasa kesulitan memahami materi keterampilan menulis sehingga dibutuhkan motode pembelajaran yang tepat. Peneliti mencoba metode pembelajaran Two Stay Two Stray dalam pembelajaran keterampilan menulis. Metode TSTS ini adalah cara siswa berbagi pengetahuan dan pengalaman dengan kelompok lain. Dengan tujuan untuk menjadikan proses belajar mudah dan menyenangkan. Metode eksperimen menggunakan pendekatan kuantitatif dengan quasi eksperimen terdiri dari 2 kelompok, yaitu kelompok eksperimen dan kontrol. Instrumen pengumpulan data: dokumentasi, observasi, pre-tes dan posttes. Hasil penelitian ini: (1) pembelajaran menulis dengan metode Two Stay Two Stray efektif dengan hasil hitungan t-tes yang menunjukkan bahwa hasil thitung adalah 6,78 lebih besar dari t-tabel (tabel signifikan) $1 \%=2,39$ dan $5 \%=1,67$, dengan demikian hipotesis peneliti dapat diterima.

@ Education, Quality, Redirection, Reevaluation

http:// http://ejournal.uin-malang.ac.id/index.php/abjadia/article/view/5361

\section{(C) مقدمة}

فإن الكتابة تعد في الواقع مفخرة العقل الإنساني بل إنها أعظم ما أنتجاه العقل وقد ذكر علماء الانثربولوجي أن الإنسان حين اخترع الكتابة بدأ تاريخه الحقيقي. هي وسيلة من وسـائل الاتصال وهي وسيلة للتعبير عما في النفس والخاطر. وهي أداة مهمة ليبان ما تم تحصلية من معلومات وهي وسيلة للتفكير المنظم والإتقان وقت الملاحظة (الله 2008).

والمشكلات التي تواجه الطلاب في الكتابة : (1) عجز التلميذ عن مسك القلم بالطريق الصحيحة؛ (2) عدم استيفاء التلميذ نقط الحروف؛ (3) التدريب على كتابة هذه الحروف والتركيز؛ (4) تعليق كلمات فيها حروف منقو طة وأخرى غير منقوطة حتى يدركوا الحروف المنقطة والحروف غير المنقوطة؛ (5) خطأ التلميذ في كتابة بعض الحروف؛ (6) عدم مراعاة نظام السطر عند الكتابة؛ (7) عدم وضوخ الكتابة؛ (8) ترك التلاميذ اللام الشمسية عند الكتابة. الجوانب المهمة في مهارة الكتابة بعض الأشياء مراعتها مهما في تعليم مهارة الكتابة: (1) الكتابة من اليمينالى اليسار بالنسبة للحروف؛ (2) التناسب بين الحروف أفقيا وراسيا ومراعاة المسافات؛ (3) الحروف التي تكون فوق السطر والحروف التي تكون تحت السطر؛ (4) اختلاف ارتفاعات الحروف التي تكون فوق السطر؛ (5) المسافات بين الحروف المتشابهة للتمييز بينها؛ (6) تعويد الدارس على طريقة الكتابة (النسخ و الرقعة) مند البداية لأهمية الأول في القراءة والثانية فى الكتابة السريعة (الخطيب 2003). 
طريقة (Two Stay Two Stray) هو طريقة التعلم التعاون على شكل اثنين من الترلاء المقيمين اثنين. هذا الطريقة تم تطويره من قبل سبنير كاجان (Spancer Kagan) في عام 1992. هيكل ضيفين اثنين مجرد اعطاء فرصة المجموعة لتقاسم النتائج والمعلومات مع المجموعات الأخرى (Ibrahim 2000). طريقة (Two هو طريقة التعلم مع المجموعة الآخر ليعطي النتيجة المعلومة. أهداف هذا الطريقة ويتعرض الطلاب لأنشطة الاستماع إلى ما يعبر عنـه صديقه بينما كان في زيارة، الذي غير مباشر ستتخذ الطلاب للاستماع ثم الكتابة إلى ما أعرب عنه أعضياء المجموعة الذين استضيافتهم. في هذه العملية،سيكون هناك أنشطة في الطلاب الاستماع و الكنابة إل هذه المادة.

من خصائص طريقة (Two Stay Two Stray) هي : (1) الطلاب يعمل في مجموعات يتعاونية ليقضي مواد الدراسية؛؛ (2) تتكون مجموعات من الطلاب الذين لديهم القدرة على العالي والمتوسط والمنخفض؛ (3) أعضاء كلما كان ذلك ممكنا من المجموعات هم من العنصري والثقافي والعرقي والجنس مختلفة؛ (4) يعطى البحث عن مجموعة أكثر توجها من الأفراد.

خطوات طريقة Two Stay Two Stray هي: (1) قسمت المدرس من التلاميذ أن يجعل مجموعاة, كل مجموعة أربعة أشخاص؛ (2) قسمت المدرس الوظيفة في كل مجموعات؛ (3) تطبيق طريقة Two Stay Two Stray مزايا طريقة (Two Stay Two Stray) هي: (1) يمكن أن يطبيقه في جميع المدارس على كل المستويات؛ (2) ميل الطالب في التعلم أصبح توجها وحيويا؛ (3) يتطلب من التلاميذ أكثر نشاطا واستجابة للعمل الجماعي؛ (4) خلق البيئة مساعدة العالية؛؛ (5) يستطيع ترقية مهارة الطلاب؛ (6) مساعدة زيادة التحصيل الدراسي. أما عيوب طريقة (Two Stay Two Stray) فهي: (1) يحتاج وقتا طويلا؛ (2) لكل مجموعاة تلميذ بقدرة منخفضية؛ (3) الدرس في حاجة إلى تحضير المواد الكثيرة والقوى العاملة والوقت الطويل (Ibrahim 2000). استنادا من المشكلات التي تواجه الطلاب في الكتابة فقدمت الكاتبة أسئلة البحث: هل استخدام طريقة (Two Stay Two Stray) فعال في ترقية مهارة الكتابة في مدرسـة هداية المبتدئين المتوسطة الإسلامية لوووك وارو مالانق؟

\section{[من}

إن منهجية البحث المستخدمة هي المنهج التجربي يعني شباه التجريبية (Quasi Eksperimental Design) بالنوع Sugiyono n.d) Nonequivalent Control Group Design)، واستخدمت الباحثة في هذا البحث بالمدخل الكمي. يجري هذا البحث باستخدام مجموعتين، هو المجموعة التجربة والمجموعة الضيابطة. 
إن مجتمع هذا البحث جميع التلاميذ في الفصل الثاني في مدرسة هداية المبتدئين المتوسّطة الإسلاميّة مالانق السنة الدراسية 2015-2016 م, وعينة البحث في الفصل الثاني "ب" المجموعاة التجربية والفصل الثاني "ج" المجموعاة الضيابطة. عن طريقة غارض المعينة (Purposive Sampling). والفصل الثاني "ب" عدد تلاميذها 32 تلاميذا. والفصل الثاني "ج" عدد تلاميذها 32 تلاميذا. عينة البحث هي بعض من السكان أو جزء صغير من المجتمع.

أما أدوات جمع البيانات المستخدمة فهي: الملاحظة، المقابلة، الاختبار، الوثيقة. ويستخدم هذا البحث طريقة جمع البيانات الكمّية التي تهدف إلى معرفة حصيول النتيجة الإختبار القبلي والإختبار البعدي. و تحليل البيانات في هذا البحث باستخدام الرموز (t-test) .

\section{نتائج}

مدرسة هداية المبتدئين المتوسطة مالانج هي إحدى المدارس التابعة لمعهد هداية المبتدئين السلفي العصري بتاسيكمادو بمالانج. يقع هذا المعهد في شارع كياهي الحاج يوسف رقم 1 بقرية تاسيكمادو بمالانج جاوى الشرقية. ويبعد عن مدينة مالانج حوالي 6.5 كيلومتر في الاتجاه الشمالي، وتبلغ مساحته حوالي 3280 كم.

أسّس الشيخ الحاج أغوس سالم محفوظ يوسف معهد هداية المبتدئين في السنة 1972 م، وفي بداية تأسيسها درس فياء تسعة طلاب وسكنوا في بيته البسيط، ثم تطوّر هذا المعهد بجهده تطوّرا سريعا. وفي السنة 1989 م أسّس الشيخ الحاج أغوس سالم محفوظ يوسف مؤسسة هداية المبتدئين للتعليم الإسلامي. طريقة المدرس المستخدمة في تعليم اللغة العربية هي باطريقة المباشرة, الإنتقائية، ووسائل الغناء, ولكن لا تجد الباحثة استخدام طريقة Two Stay Two Stray في هذه المدرسـة. وهناك مشكلات بعض التلاميذ في تعليم اللغة العربية و خصائصها في مهارة الكتابة. خطط التدريس في هذه الطريقة

الأول: قسمت المدرسة من التلاميذ؛ قبل تبدأ عملية التعليم قسمت المدرسة من التلاميذ أن يجعل مجموعة،, و هناك عدد التلاميذها 32 تلاميذا. و قسمت المدرسة 8 مجموعات و في كل مجموعة 4 أعضاء. والثاني: قسمت الوظيفة؛ بعد شرحت المدرسة عن المادة الدراسية ثم قسمت المدرسة الوظيفة إلى كل التلاميذ. و هذه الوظيفة لمعرفة قدرة التلاميذ في مفاهيم المادة. و بعد ذلك أمرت المدرسة إلى كل مجموعات ليكتب الفقرة بمناسبة المادة. 
والثالث: تطبيق طريقة Two Stay Two Stray؛ بعد انتهاء, يذهب التلميذان إلى مجموعة الأخرى ليطلب المعلومات الجديدة عن الفقرته. و التلميذان في مجموعتها ليعطى المعلومات إلى ضيوفهم. والرابع: تحليل المعلومات؛ بعد يطلب المعلومات الجديدة هم تحليل المعلومات مع صيديقتهم في كل

والخامس: خلاصة؛؛ في أخير عملية التعليم, تعطي المدرسة الخلاصة عملهم عن المادة الدراسية.

نتائج الاختبار القبلي للمجمموعة الضـابطة

\begin{tabular}{|c|c|c|c|}
\hline التقدير & الاختبار القبلي & اسماء التلاميذ & الرقم - ال \\
\hline ضعيف & 50 & ا. أ. ليل القدر & 1 \\
\hline ضعيف & 55 & أديتيا فيرمانشـة & 2 \\
\hline ضعيف & 60 & ألفي زهرة المودّة & 3 \\
\hline ضعيف & 50 & أنجيلي سيلفي سافيتري & 4 \\
\hline ضعيف & 60 & أريا مولانا مغربي & 5 \\
\hline ضيعيف & 55 & أوليا رحم سلسابيلا & 6 \\
\hline ضعيف & 60 & بصري علوي & 7 \\
\hline ضيعيف & 50 & ديديك سيتيياوان & 8 \\
\hline ضيعيف & 60 & اينديكا باجاس دونيارطا & 9 \\
\hline ضيعيف & 55 & فاني أديتيا فراتاما & 10 \\
\hline ضيعيف & 55 & فاني ريزا & 11 \\
\hline ضيعيف & 60 & فاريد كورنياوان & 12 \\
\hline ضيعيف & 60 & فيرا لوسييانا فوتري & 13 \\
\hline مقبول & 65 & حفيف فضالي & 14 \\
\hline ضعيف & 60 & اشرفية نور رافقة & 15 \\
\hline ضعيف & 50 & محمد نور إبراهيم & 16 \\
\hline ضعيف & 50 & محمد رافقي كورنيياون & 17 \\
\hline ضعيف & 60 & مانجارونجي انجارا & 18 \\
\hline ضعيف & 55 & محمد ريفالدو & 19 \\
\hline ضيعيف & 60 & محمد امام اوتاما & 20 \\
\hline ضعيف & 60 & محمد ريكو & 21 \\
\hline ضعيف & 60 & ناتاشا ايماليا فوتري & 22 \\
\hline مقبول & 65 & روسال ديفينو & 23 \\
\hline ضعيف & 60 & رحمة ويدودو & 24 \\
\hline ضعيف & 55 & سيلين دياه روسا & 25 \\
\hline مقبول & 65 & تيا ديانيغسية & 26 \\
\hline مقبول & 70 & يولنيني انّيسا. و & 27 \\
\hline ضعيف & 60 & يونيتا ألدينا. س & 28 \\
\hline ضعيف & 55 & ريحان بايو & 29 \\
\hline ضيعيف & 60 & مونيجا فوتري & 30 \\
\hline ضعيف & 60 & يوجا ستياوان & 31 \\
\hline مقبول & 65 & رفكي. أ & 32 \\
\hline \multicolumn{2}{|c|}{1865} & \multicolumn{2}{|l|}{ العدد } \\
\hline \multicolumn{2}{|c|}{58,28} & \multicolumn{2}{|l|}{ المعدل } \\
\hline
\end{tabular}


فمن نتائج هذا الاختبار القبلي, ظهر أن التلاميذ نالوا الدرجة المعدلة 58,28 وأما التلاميذ في مستوى ممتاز = 0 وفي مستوى جيد جدا = 0 وفي مستوى جيد = 0 وفي مستوى مقبول = 5 وفي مستوى ضعيف = 27 و من هنا فإن قدرتهم على مهارة الكتابة بصفة ضعيفة.

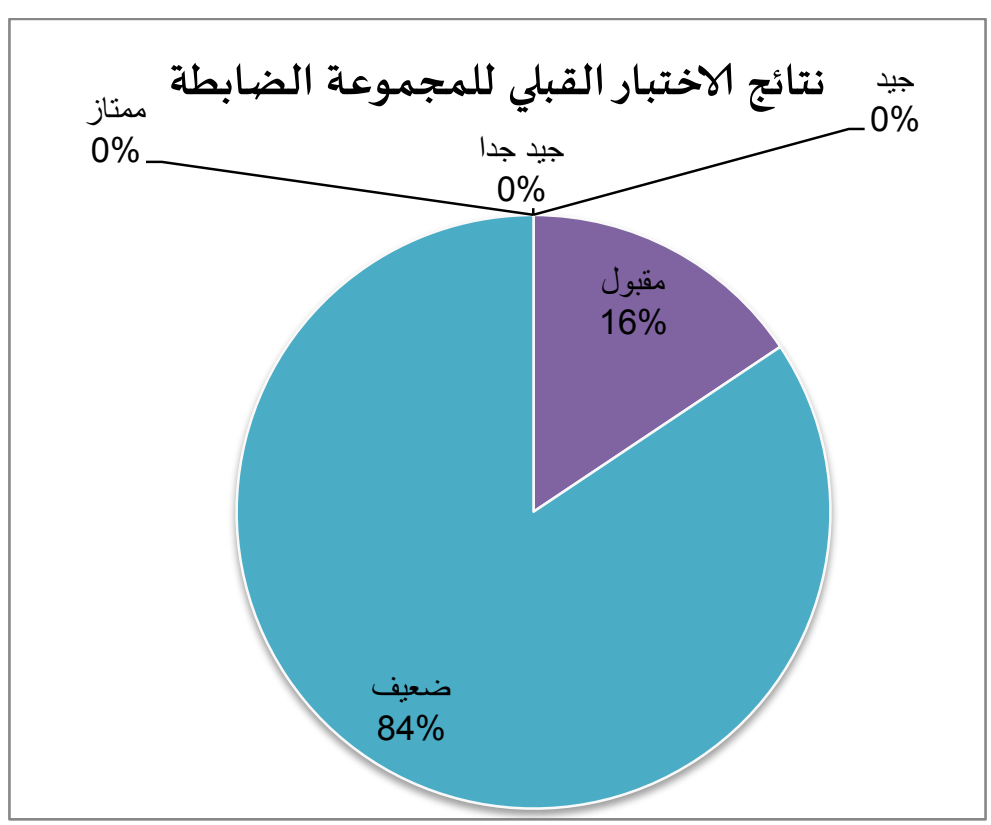

نتائج الاختبار البعدي للمجموعة الضيابطة

\begin{tabular}{|c|c|c|c|}
\hline التقدير & الاختبار البعدي & اسـماء التلاميذ & الرقم \\
\hline مقبول & 65 & ليل القدر & 1 \\
\hline مقبول & 65 & أديتيا فيرمانشة & 2 \\
\hline مقبول & 70 & ألف زهرة المودّة & 3 \\
\hline مقبول & 70 & أنجيلي سيلفي سافيتري & 4 \\
\hline مقبول & 70 & أريا مولانا مغربي & 5 \\
\hline ضعيف & 60 & أوليا رحم سلسابيلا & 6 \\
\hline مقبول & 70 & بصري علوي & 7 \\
\hline مقبول & 60 & ديديك سيتيياوان & 8 \\
\hline مقبول & 70 & اينديكا باجاس دونيارطا & 9 \\
\hline مقبول & 65 & فاني أديتيا فراتاما & 10 \\
\hline مقبول & 70 & فاني ريزا & 11 \\
\hline مقبول & 70 & فاريد كورنياوان & 12 \\
\hline جيد & 75 & فيرا لوسييانا فوتري & 13 \\
\hline جيد & 75 & حفيف فضالي & 14 \\
\hline جيد & 75 & اشرفية نور رافقة & 15 \\
\hline مقبول & 65 & محمد نور إبراهيم & 16 \\
\hline مقبول & 65 & محمد رافقي كورنيياون & 17 \\
\hline مقبول & 70 & مانجار ونجي انجارا & 18 \\
\hline مقبول & 65 & محمد ربفالدو & 19 \\
\hline مقبول & 65 & محمد امام اوتاما & 20 \\
\hline ضعيف & 60 & محمد ريكو & 21 \\
\hline جيد & 75 & ناتاشـا ايماليا فوتري & 22 \\
\hline جيد & 75 & روسال ديفينو & 23 \\
\hline
\end{tabular}




\begin{tabular}{|c|c|c|c|}
\hline مقبول & 70 & رحمة ويدودو & 24 \\
\hline مقبول & 65 & سيلين دياه روسا & 25 \\
\hline مقبول & 70 & تيا ديانيغسية & 26 \\
\hline جيد & 75 & يولنيني انتّسا. و & 27 \\
\hline مقبول & 70 & يونيتا ألدينا. س & 28 \\
\hline مقبول & 65 & ريحان بايو & 29 \\
\hline ضعيف & 60 & مونيجا فوتري & 30 \\
\hline مقبول & 70 & يوجا ستياوان & 31 \\
\hline مقبول & 70 & رفكي. أ & 32 \\
\hline \multicolumn{2}{|c|}{2185} & \multicolumn{2}{|l|}{ العدد } \\
\hline \multicolumn{2}{|r|}{68,28} & \multicolumn{2}{|c|}{ المعدل } \\
\hline
\end{tabular}

فمن نتائج هذا الاختبار البعدي, ظهر أن التلاميذ نالوا الدرجة المعدلة 68,28 وأما التلاميذ في مستوى ممتاز= 0 وفي مستوى جيد جدا= 0 وفي مستوى جيد= 6 وفي مستوى مقبول= 20 وفي مستوى ضيعيف 6 و من هنا فإن قدرتهم على مهارة الكتابة بصفة مقبولة.

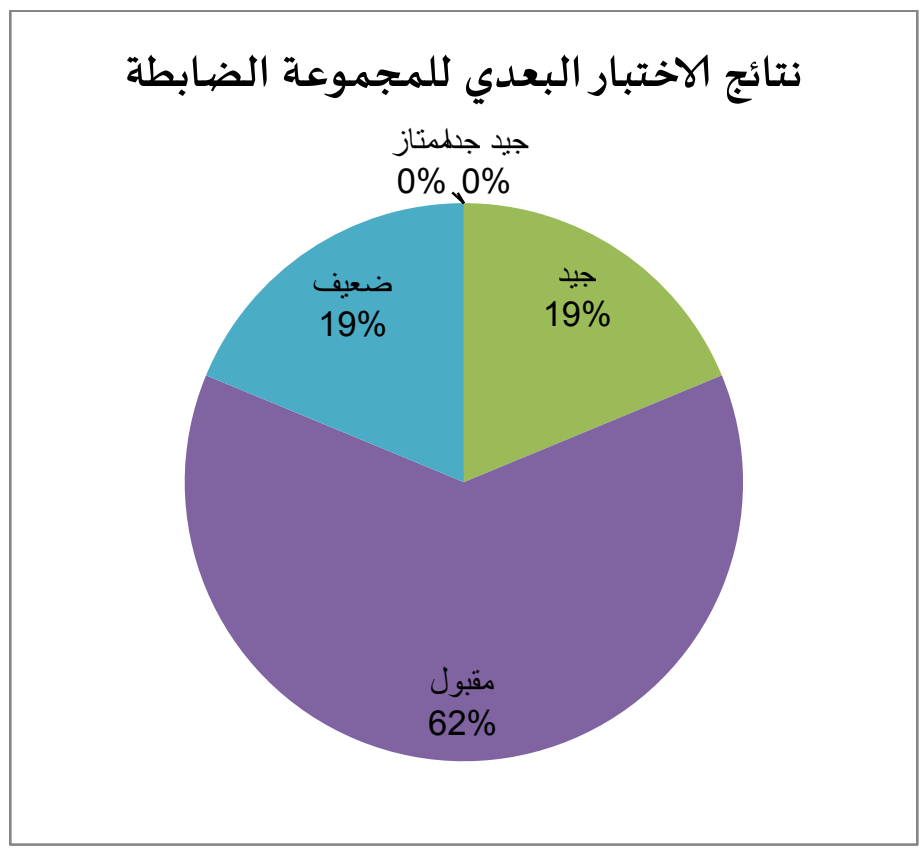

نتائج الاختبار القبلي للمجموعة التجريبة

\begin{tabular}{|c|c|c|c|}
\hline التقدير & الاختبار القبلي & اسماء التلاميذ & الرقم \\
\hline ضعيف & 50 & عبدي فيرمادي & 1 \\
\hline ضعيف & 55 & أحمد أغوين ساني & 2 \\
\hline مقبول & 65 & أدام يوسار & 3 \\
\hline ضعيف & 50 & أحمد أدي ويبووو & 4 \\
\hline ضعيف & 60 & عينول نور عزيزة & 5 \\
\hline ضعيف & 60 & ألفي روساليا & 6 \\
\hline ضعيف & 55 & أردي محمد روزابي & 7 \\
\hline ضعيف & 60 & عرّافع فرحان. ف & 8 \\
\hline ضعيف & 50 & ديكي ألفيان رادانا & 9 \\
\hline مقبول & 65 & ديكي سوبكتيّار & 10 \\
\hline
\end{tabular}




\begin{tabular}{|c|c|c|c|}
\hline ضعيف & 60 & ايكا باغوس ساجيوو & 11 \\
\hline مقبول & 65 & فبرينا انتان فاغوويتا & 12 \\
\hline مقبول & 70 & إيفا نور عزيزة & 13 \\
\hline ضيعيف & 55 & ليا فريدتول علما & 14 \\
\hline مقبول & 65 & محمد فوزان & 15 \\
\hline ضعيف & 55 & محمد مولد & 16 \\
\hline مقبول & 70 & محمد يحيا جهيانا & 17 \\
\hline ضعيف & 50 & محممد أوّل الدين & 18 \\
\hline مقبول & 65 & محمد زين المصطفى & 19 \\
\hline ضعيف & 55 & محممد ألف فيترا اسلام & 20 \\
\hline ضعيف & 60 & محمد الهام شهرول & 21 \\
\hline ضعيف & 55 & معافية & 22 \\
\hline ضعيف & 60 & محمد مولانا & 23 \\
\hline ضعيف & 55 & محمد يوجا ريسالدي & 24 \\
\hline مقبول & 65 & محمد جيفري & 25 \\
\hline ضعيف & 60 & أوسكار & 26 \\
\hline ضعيف & 55 & رافي رزق الله & 27 \\
\hline ضعيف & 55 & ريا فبريينتي & 28 \\
\hline ضعيف & 60 & سيفتينا أيو. هـ & 29 \\
\hline ضعيف & 50 & تييو هارديينشة & 30 \\
\hline مقبول & 70 & ويدي فيترياني & 31 \\
\hline ضعيف & 55 & يودا أجي فراستييو & 32 \\
\hline \multicolumn{2}{|c|}{1880} & \multicolumn{2}{|l|}{ العدد } \\
\hline \multicolumn{2}{|c|}{58,75} & \multicolumn{2}{|l|}{ المعدل } \\
\hline
\end{tabular}

فمن نتائج هذا الاختبار القبلي, ظهر أن التلاميذ نالوا الدرجة المعدلة 58,75 وأما التلاميذ في مستوى

ممتاز = 0 وفي مستوى جيد جدا = 0 وفي مستوى جيد = 0 وفي مستوى مقبول = 9 وفي مستوى ضيعيف 23.

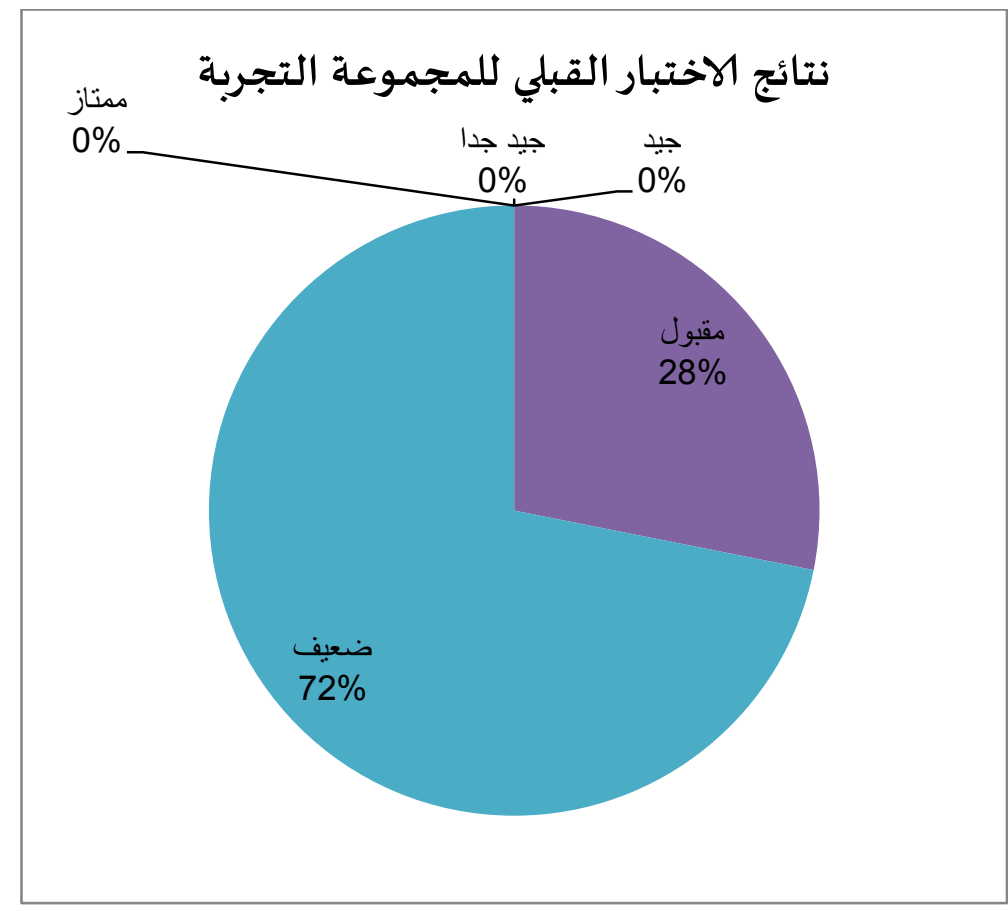


نتائج الاختبار البعدي للمجموعة التجريبة

\begin{tabular}{|c|c|c|c|}
\hline التقدير & الاختبار البعدي & اسمماء التلاميذ & الرقم \\
\hline مقبول & 70 & عبدي فيرمادي & 1 \\
\hline مقبول & 65 & أحمد أغوين ساني & 2 \\
\hline جيد جدا & 85 & أدام يوسسار & 3 \\
\hline جيد & 75 & أحمد أدي ويبووو & 4 \\
\hline جيد جدا & 85 & عينول نور عزيزة & 5 \\
\hline جيد & 75 & ألفي روساليا & 6 \\
\hline جيد & 75 & أردي محمد روزابي & 7 \\
\hline جيد جدا & 80 & عرّافع فرحان. ف & 8 \\
\hline جيد & 75 & ديكي ألفيان رادانا & 9 \\
\hline مقبول & 70 & ديكي سوبكتيّار & 10 \\
\hline جيد & 75 & ايكا باغوس ساجيوو & 11 \\
\hline جيد جدا & 80 & فبرينا انتان فاغوويتا & 12 \\
\hline ممتاز & 90 & إيفا نور عزيزة & 13 \\
\hline جيد & 75 & ليا فريدتول علميا & 14 \\
\hline جيد جدا & 80 & محمد فوزان & 15 \\
\hline جيد & 75 & محمد مولد & 16 \\
\hline جيد جدا & 85 & محمد يحيا جهيانا & 17 \\
\hline جيد & 75 & محمد أوّل الدين & 18 \\
\hline جيد & 75 & محمد زين المصطفى & 19 \\
\hline مقبول & 70 & محمد ألف فيترا اسلام & 20 \\
\hline جيد & 75 & محمد الهام شهرول & 21 \\
\hline جيد & 75 & معافية & 22 \\
\hline جيد جدا & 80 & محمد مولانا & 23 \\
\hline مقبول & 70 & محمد يوجا ريسالدي & 24 \\
\hline جيد جدا & 80 & محمد جيفري & 25 \\
\hline جيد & 75 & أوسكار & 26 \\
\hline جيد & 75 & رافي رزق الله & 27 \\
\hline مقبول & 70 & ريا فبرينتي & 28 \\
\hline جيد & 75 & سيفتينا أيو. هـ & 29 \\
\hline مقبول & 70 & تييو هارديينشة & 30 \\
\hline ممتاز & 90 & ويدي فيترياني & 31 \\
\hline جيد & 75 & يودا أجي فراستييو & 32 \\
\hline \multicolumn{2}{|c|}{2445} & \multicolumn{2}{|l|}{ العدد } \\
\hline \multicolumn{2}{|c|}{76,40} & \multicolumn{2}{|l|}{ المعددل } \\
\hline
\end{tabular}

فمن نتائج هذا الاختبار البعدي, ظهر أن التلاميذ نالوا الدرجة المعدلة 76,40 وأما التلاميذ في مستوى ممتاز = 2 وفي مستوى جيد جدا= 8 وفي مستوى جيد = 15 وفي مستوى مقبول = 7 وفي مستوى ضعيف=0. و من هنا فإن قدرتهم على مهارة الكتابة بصفة جيدة. 


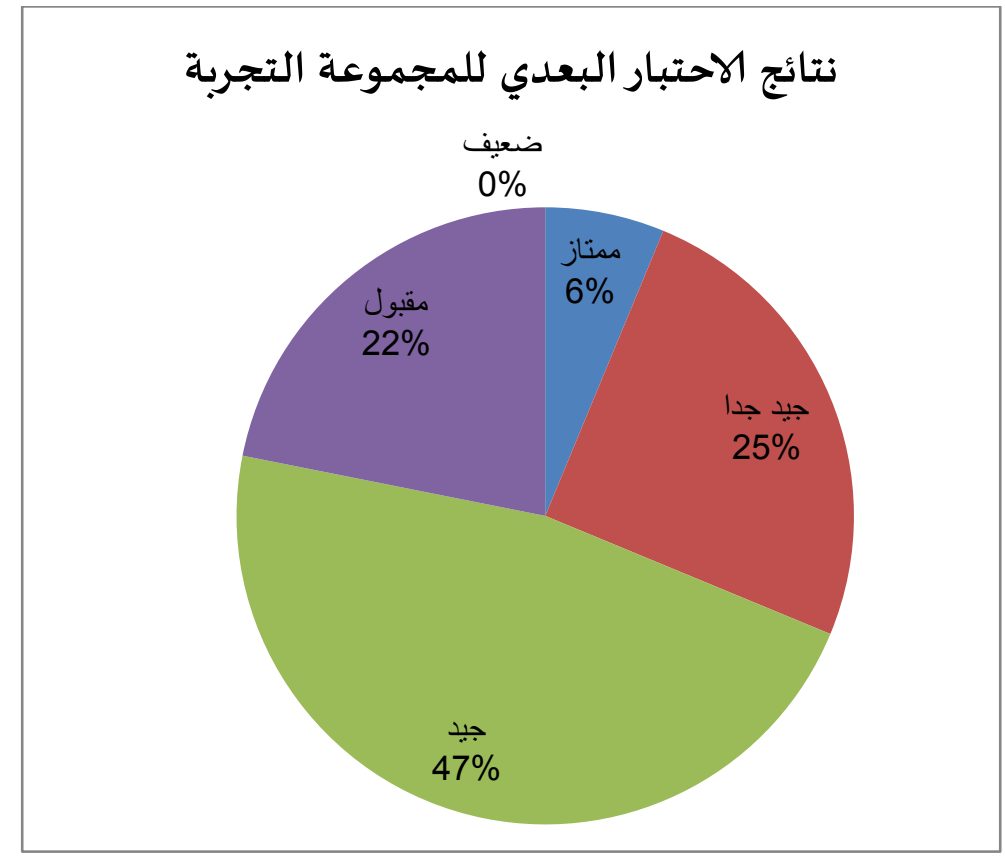

المقارنة بين الاختبار القبلي والبعدي للمجمموعة الضيابطة

\begin{tabular}{|c|c|c|c|c|c|c|}
\hline \multicolumn{2}{|c|}{ الاختبار البعدي } & \multicolumn{2}{|c|}{ الاختبار القبلي } & \multirow{2}{*}{ النتيجة } & \multirow{2}{*}{ المستوى } & \multirow{2}{*}{ الرقم } \\
\hline النسبة المئوية & عدد التلاميذ & النسبة المئوية & عدد التلاميذ & & & \\
\hline - & - & - & - & $100-90$ & ممتاز & 1 \\
\hline - & - & - & - & $89-80$ & جيد جدا & 2 \\
\hline$\% 18,75$ & 6 & - & - & $79-75$ & جيد & 3 \\
\hline$\% 62,5$ & 20 & $\% 15,62$ & 5 & $74-65$ & مقبول & 4 \\
\hline$\% 18,75$ & 6 & $\% 84,37$ & 27 & $64-0$ & ضعيف & 5 \\
\hline \%100 & 32 & \%100 & 32 & & العدد & \\
\hline
\end{tabular}

وبالنسبة إلى بيان المقارنة بين الاختبار القبلي و البعدي للمجموعة الضابطة فظهر أن في الاختبار القبلي 84,37\% من التلاميذ في مستوى ضعيف, وفي مستوى مقبول 15,62\%. وأما في الاختبار البعدي ظهر أن ضعيف 18,75\%, و في مستوى مقبول 62,5\%, وفي مستوى جيد 18,75\%. وهذا البيان يعني السابق أن نتيجة الاختبار البعدي أكثر من نتيجة الاختبار القبلي.

المقارنة بين الاختبار القبلي والبعدي للمجموعة التجريبة

\begin{tabular}{|c|c|c|c|c|c|c|}
\hline \multicolumn{2}{|c|}{ الاختبار البعدي } & \multicolumn{2}{|c|}{ الاختبار القبلي } & \multirow{2}{*}{ النتيجة } & \multirow{2}{*}{ المستوى } & \multirow{2}{*}{ الرقم } \\
\hline النسبة المئوية & عدد التلاميذ & النسبة المئوية & عدد التلاميذ & & & \\
\hline$\% 6,25$ & 2 & - & - & $100-90$ & ممتاز & 1 \\
\hline$\% 25$ & 8 & - & - & $89-80$ & جيد جدا & 2 \\
\hline \%46,87 & 15 & - & - & $79-75$ & جيد & 3 \\
\hline$\% 21,87$ & 7 & $\% 28,12$ & 9 & $74-65$ & مقبول & 4 \\
\hline- & - & $\% 71,87$ & 23 & $64-0$ & ضعيف & 5 \\
\hline \%100 & 32 & $\% 100$ & 32 & & العدد & \\
\hline
\end{tabular}


وبالنسبة إلى بيان المقارنة بين الاختبار القبلي و البعدي للمجموعـة التجريبة فظهر أن في الاختبار القبلي 71,87\% من التلاميذ في مستوى ضعيف, وفي مستوى مقبول 28,12\%. وأما في الاختبار البعدي ظهر أن 21,87\% من التلاميذ في مستوى مقبول, وفي مستوى جيد 46,87\%, وفي مستوى جيد جدا 25\%, وفي مستوى ممتاز 6,25\% . وهذا البيان يعني السابق أن نتيجة الاختبار البعدي أكثر من نتيجة الاختبار

المقارنة نتائج الاختبار البعدي للمجموعة الضـابطة والتجريبة

\begin{tabular}{|c|c|c|c|c|}
\hline الاختبار البعدي & أسماء المجمموعة التجربة & الاختبار البعدي & أسماء المجمموعة الضـابطة & الرقم - الرم \\
\hline 70 & عبدي فيرمادي & 65 & ليل القدر & 1 \\
\hline 65 & أحمد أغوين ساني & 65 & أديتيا فيرمانشة & 2 \\
\hline 85 & أدام يوسار . & 70 & ألف زهرة المودّة & 3 \\
\hline 75 & أحمد أدي ويبووو & 70 & أنجيلي سيلفي. س & 4 \\
\hline 85 & عينول نور عزيزة & 70 & أريا مولانا مغربي & 5 \\
\hline 75 & ألفي روساليا & 60 & أوليا رحم سلسابيلا & 6 \\
\hline 75 & أردي محمد روزابي & 70 & بصري علوي & 7 \\
\hline 80 & عرّافع فرحان. ف & 60 & ديديك سيتيياوان & 8 \\
\hline 75 & ديكي ألفيان رادانا & 70 & اينديكا باجاس. د & 9 \\
\hline 70 & ديكي سوبكتيّار & 65 & فاني أديتيا فراتاما & 10 \\
\hline 75 & ايكا باغوس. س & 70 & فاني ريزا & 11 \\
\hline 80 & فبرينا انتان. ف & 70 & فاريد كورنياوان & 12 \\
\hline 90 & إيفا نور عزيزة & 75 & فيرا لوسييانا فوتري & 13 \\
\hline 75 & ليا فريدتول علميا & 75 & حفيف فضالي & 14 \\
\hline 80 & محمد فوزان & 75 & اشرفية نور رافقة & 15 \\
\hline 75 & محمد مولد & 65 & محمد نور إبراهيم & 16 \\
\hline 85 & محمد يحيا جهيانا & 65 & محمد رافقي. ك & 17 \\
\hline 75 & محمد أوّل الدين & 70 & مانجار ونجي انجارا & 18 \\
\hline 75 & محمد زين المصطفى & 65 & محمد ريفالدو & 19 \\
\hline 70 & محمد ألف فيترا. ! & 65 & محمد امام اوتاما & 20 \\
\hline 75 & محمد الهام شهرول & 60 & محمد ريكو & 21 \\
\hline 75 & معافية & 75 & ناتاشا ايماليا فوتري & 22 \\
\hline 80 & محمد مولانا & 75 & روسال ديفينو & 23 \\
\hline 70 & محمد يوجا.ر & 70 & رحمة ويدودو & 24 \\
\hline 80 & محمد جيفري & 65 & سيلين دياه روسا & 25 \\
\hline 75 & أوسكار & 70 & تيا ديانيغسية & 26 \\
\hline 75 & رافي رزق الله & 75 & يولنيني انّيسا. و & 27 \\
\hline 70 & ريا فبريينتي & 70 & يونيتا ألدينا. س & 28 \\
\hline 75 & سيفتينا أيو. هـ & 65 & ريحان بايو & 29 \\
\hline 70 & تييو هارديينشة & 60 & مونيجا فوتري & 30 \\
\hline 90 & ويدي فيترياني & 70 & يوجا ستياوان & 31 \\
\hline 75 & يودا أجي فراستييو & 70 & رفكي. أ & 32 \\
\hline 2445 & المجموعة & 2185 & المجموعة & $\mathrm{N}$ \\
\hline
\end{tabular}


ظهر من الجدول السابق أن نتائج الاختبار البعدي للمجموعة التجريبة = 2445 أكبر من نتائج

$$
\text { الاختبار البعدي للمجموعاة الضابطة = } 2185 .
$$

نتائج عدد الإنحراف وعدد الإنحراف المربع من المجموعتين

\begin{tabular}{|c|c|c|c|c|c|c|c|c|}
\hline \multicolumn{4}{|c|}{ المجموعة التجريبة } & \multicolumn{4}{|c|}{ المجموعة الضيابطة } & \multirow{2}{*}{ الرقم } \\
\hline$x^{2}$ & $(x)$ & $x_{2}$ & $x_{1}$ & $y^{2}$ & $(y)$ & $y_{2}$ & $y_{1}$ & \\
\hline 400 & 20 & 70 & 50 & 225 & 15 & 65 & 50 & 1 \\
\hline 100 & 10 & 65 & 55 & 100 & 10 & 65 & 55 & 2 \\
\hline 400 & 20 & 85 & 65 & 100 & 10 & 70 & 60 & 3 \\
\hline 625 & 25 & 75 & 50 & 400 & 20 & 70 & 50 & 4 \\
\hline 625 & 25 & 85 & 60 & 100 & 10 & 70 & 60 & 5 \\
\hline 225 & 15 & 75 & 60 & 25 & 5 & 60 & 55 & 6 \\
\hline 400 & 20 & 75 & 55 & 100 & 10 & 70 & 60 & 7 \\
\hline 400 & 20 & 80 & 60 & 100 & 10 & 60 & 50 & 8 \\
\hline 625 & 25 & 75 & 50 & 100 & 10 & 70 & 60 & 9 \\
\hline 25 & 5 & 70 & 65 & 100 & 10 & 65 & 55 & 10 \\
\hline 225 & 15 & 75 & 60 & 225 & 15 & 70 & 55 & 11 \\
\hline 225 & 15 & 80 & 65 & 100 & 10 & 70 & 60 & 12 \\
\hline 400 & 20 & 90 & 70 & 225 & 15 & 75 & 60 & 13 \\
\hline 400 & 20 & 75 & 55 & 100 & 10 & 75 & 65 & 14 \\
\hline 225 & 15 & 80 & 65 & 225 & 15 & 75 & 60 & 15 \\
\hline 400 & 20 & 75 & 55 & 225 & 15 & 65 & 50 & 16 \\
\hline 225 & 15 & 85 & 70 & 225 & 15 & 65 & 50 & 17 \\
\hline 625 & 25 & 75 & 50 & 100 & 10 & 70 & 60 & 18 \\
\hline 100 & 10 & 75 & 65 & 100 & 10 & 65 & 55 & 19 \\
\hline 225 & 15 & 70 & 55 & 25 & 5 & 65 & 60 & 20 \\
\hline 225 & 15 & 75 & 60 & 0 & 0 & 60 & 60 & 21 \\
\hline 400 & 20 & 75 & 55 & 225 & 15 & 75 & 60 & 22 \\
\hline 400 & 20 & 80 & 60 & 100 & 10 & 75 & 65 & 23 \\
\hline 225 & 15 & 70 & 55 & 100 & 10 & 70 & 60 & 24 \\
\hline 225 & 15 & 80 & 65 & 100 & 10 & 65 & 55 & 25 \\
\hline 225 & 15 & 75 & 60 & 25 & 5 & 70 & 65 & 26 \\
\hline 400 & 20 & 75 & 55 & 25 & 5 & 75 & 70 & 27 \\
\hline 225 & 15 & 70 & 55 & 100 & 10 & 70 & 60 & 28 \\
\hline 225 & 15 & 75 & 60 & 100 & 10 & 65 & 55 & 29 \\
\hline 400 & 20 & 70 & 50 & 0 & 0 & 60 & 60 & 30 \\
\hline 400 & 20 & 90 & 70 & 100 & 10 & 70 & 60 & 31 \\
\hline 400 & 20 & 75 & 55 & 25 & 5 & 70 & 65 & 32 \\
\hline 10625 & 565 & 2445 & 1880 & 3800 & 320 & 2185 & 1865 & المجموع \\
\hline$\sum x^{2}$ & $\sum x$ & & & $\sum \boldsymbol{y}^{2}$ & $\sum y$ & & & \\
\hline
\end{tabular}


وبعد توضيح الجدول السابق، تخلص الباحثة بعض النتائج الآتية عدد الإنحراف، ومجموعة عدد الإنحراف المربع من المجموعة الظابطة والمجموعة التجريبة مجموع عدد الإنحراف وعدد الإنحراف المربع من المجموعتين

\begin{tabular}{|c|c|c|c|}
\hline \multicolumn{2}{|c|}{ المجموع التجريبة } & \multicolumn{2}{|c|}{ المجموع الضـابطة } \\
\hline $\begin{array}{c}\text { عدد الإنحراف المربع } \\
\left(\sum x^{2}\right)\end{array}$ & $\begin{array}{c}\text { مجموع عدد الإنحراف } \\
\left(\sum x\right)\end{array}$ & $\begin{array}{c}\text { عدد الإنحراف المربع } \\
\left(\sum \boldsymbol{y}^{2}\right)\end{array}$ & $\begin{array}{c}\text { مجموع عدد الإنحراف } \\
\left(\sum \boldsymbol{y}\right)\end{array}$ \\
\hline 10625 & 565 & 3800 & 320 \\
\hline
\end{tabular}

من الجدوال السـابق وجدت الباحثة أن نيجة t الإحصائي = 6,78 ثم قامت الباحثة بتعيين t-table ثم بحثت الباحثة نتيجتاه في القائمة الحرية (degree of freedom) من t-table فوجد أن نتيجتاه في المستوى المعنوى 1\% = 2,39 و في المستوى المعنوى 5\% = 1,67. وهذا تقرير"ت (t)":

"تقرير "ت (t)

$$
\begin{aligned}
& \text { t الجدوالي (t.tabel > (الحسابي t t.test } \\
& \text { t الجدوالي (t.tabel > ( الحسـابي ) t.test }
\end{aligned}
$$

ونتيجة الإحصائي = 6,78 أكبر من نتيجة المستوى المعنوى 1\% = 2,39 وكذلك أكبر من نتيجة المستوى المعنوى 5\% = 1,67, بمعنى أن Ho مردود و H1 مقبول أي أن فروض البحث مقبولة, والخلاصية أن استخدام أسلوب (Two Stay Two Stray) له أثارلترقية كفاءة التلاميذ في تعليم مهارة الكتابة.

\section{مُبْزَ مناقشَة}

فعالية استخدام طريقة Two Stay Two Stray لترقية مهارة الكتابة, أن تعليم مهارة الكتابة باستخدام طريقة Two Stay Two Stray في مدرسة هداية المبتدئين المتوسطة الإسلامية لوووك وارو مالانج فعال. بدليل أن نتيجة "t" 6,78 أكبر من نتيجة المستوى المعنوى 1\% = 2,39 وكذلك أكبر من نتيجاة المستوى المعنوى 5\% = 1,67. وذلك بمعنى أن فروض هذا البحث مقبول. وخلاصتها أن استخدام طريقة Two Stay Two Stray لترقياة مهارة الكتابة في مدرسة هداية المبتدئين المتوسطة الإسلامية لوووك وارو مالانج فعالية و تنمية رغبة و دافع التلاميذ في تعليم مهارة الكتابة. اعتماد على نتائج الاختبار القبلي و البعدي للمجموعة التجريبية و الضابطة التي حصل التلاميذ, قد وجدت الباحثة بينما فرقا وضحا. و هذا يدل على أن استخدام طريقة Two Stay Two Stray له تأثير كبير 
في تعليم مهارة الكتابة. معظم التلاميذ يحبون التعلّم باستخدام طريقة Two Stay Two Stray , لأن التلاميذ يفهمون المادة الدراسـة بسرعة و تساعدهم على نجاح التعلم.

من جانب النظر في هذا الظروف الأحسان المدرس يستخدم الطريقة التعليمية في تحقيق أهدافها وتجعل تشوق التلاميذ للدرس و توجيا اهتمامهم أليه و تجعل ما يتعلمونه باقيا و مستمرا و تسـاعدهم على سرعة تذكير

نماذج التعليم (Two Stay Two Stray)

نماذج التعليم (Two Stay Two Stray) يتألف من عدة مراحل كما يلى:

الأول: الإعداد؛ وهو أن يصمم المدرس في مرحلة الإعداد المناهج والتقييم والتصميم التعليمي, ثم قسم المدرس التلاميذ إلى عدة مجموعات مع 4 أعضياء لكل منها, ولكل عضو من أعضياء المجموعة يجب أن يكون متجانسا من حيث الجنس والتحصيل الدراسي لدى التلاميذ. بعد ذلك, قدم المدرس الاختبار لتحديد قدرة التلاميذ في وقت مبكر. والثاني: العرض من التلاميذ؛ في هذه المرحلة, قدم المدرس مؤشرات التعلم والتعريف عليها وشرح المواد وفقا لخطط الدروس المصيممة. والثالث: الأنشطة المشتركة؛ في هذا النشط, استخدام المدرس ورقة النشاط التى تحتوي على الوظيفات يجب أن يتعلمها كل طالب في المجموعة. بعد ما تلقي التلاميذ ورقة النشاط التي تحتوي على المسائل المتعلقة. بمفهوم المواد وتصنيفها, يتعلم التلاميذ في مجموعاة صغيرة ويناقشهامع أصبدقائهم في مجموعة. ثم ترك من 4 أعضاء في كل مجموعة لزيارة إلى المجموعة الأخر, في حين أن 2الأعضياء الذين يقيمون في المجموعة وزعا الوظيفة وحملاها على ضيوفها. بعد الحصول على معلومات من الأعضاء 2 الذين يبقون. عذر الضيوف وعاد إلى مجموعاتهم وقدم تقريرا عن نتائج المجموعات الأخرى قبل ومناقشـة نتائج عملههم.

والرابع: إضفاء الطابع الرسمي؛ بعد دراسة في المجموعات وحل المشاكل المعيناة, قدمت مجموعاة واحدة من نتائج مناقشة المجموعة لإبلاغها أو مناقشتها مع المجموعات الأخرى. ثم مناقشة المدرس وتوجيها إلى شكل رسمي. 


\section{خاتمة}

وبعد انتهاء من إجراء البحث الجامعي عن استخدام طريقة Two Stay Two Stray في تعليم مهارة

الكتابة في مدرسة هداية المبتدئين المتوسطة الإسلامية لوووك وارو مالانج, فحصلت الباحثة من الملاحظات التي عقدت الباحثة أن استخدام طريقة Two Stay Two Stray لترقية مهارة الكتابة لها أثر, لأن التلاميذ يشعرون بالحماسة و الرغبة في عملية التعليم. وهذه الطريقة كانوا يستطيعون أن يتعاون بعضهم ببعض و تجعل عملية التعليم ممتعة.

أن استخدام طريقة Two Stay Two Stray لترقية مهارة الكتابة فعالية, بنتيجة الإحصائي =

6,78 أكبر من نتيجة المستوى المعنوى 1\% = 2,39 وكذلك أكبر من نتيجة المستوى المعنوى 5\% = 1,67,

بمعنى أن Ho مردود و H1 مقبول أي أن فروض البحث مقبولة, والخلاصة أن استخدام أسلوب ( Two (Stay Two Stray لله أثار لترقياة كفاءة التلاميذ في تعليم مهارة الكتابة.

Ibrahim, M. 2000. Pembelajaran Kooperatif. Surabaya: Universitas Negeri Surabaya University Press.

Sugiyono. n.d. Metode Penelitian Kuantitatif Kualitatif Dan RED. Bandung: Alfabeta.

الخطيب, محمد بن إبراهيم. 2003. طرائق تعليم اللغة العببية. الرياض: المملكة العربية السعودية. الله, عمر الصديق عبد. 2008. تعليم اللغة للناطقين بغيرها. الخرطوم: الدار العالمية.

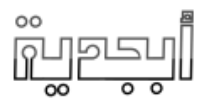

